\title{
Milano Città d'Acqua, un debate actual en torno a la recuperación del patrimonio hidráulico
}

\section{Milano Città d'Acqua, a current discussion related to water heritage recovery}

\author{
CELIA LÓPEZ-BRAVO - ANTONELLA CONTIN - EDUARDO MOSQUERA ADELL
}

Celia López-Bravo, Antonella Contin, Eduardo Mosquera Adell, "Milano Città d'Acqua, un debate actual en torno a la recuperación del patrimonio hidráulico", ZARCH 15 (diciembre 2020): 122-137. ISSN versión impresa: 2341-0531 / ISSN versión digital: 2387-0346. https://doi.org/10.26754/ojs_zarch/zarch.2020154620

Recibido: 10-06-2020 / Aceptado: 02-09-2020

\section{Resumen}

Pese a asentarse sobre un estrato hídrico que la abastece naturalmente, Milán ha dedicado incansables esfuerzos a establecer una red hidráulica como conexión con otras ciudades. Esta planificación ingenieril le permitió construir un extenso sistema de canales navegables, salvando distancias hasta los ríos más próximos. Por ello fue denominada la Città dell'acqua. Paradójicamente, la idea de prescindir de estas aguas antropogénicas surgió de uno de sus primeros planes urbanísticos a finales del XIX. Este artículo caracteriza la ciudad cronológicamente, centrándose en su hidrografía y sus obras hidráulicas medievales y modernas, los llamados navigli. A continuación, se exponen los argumentos urbanos que, tras la industrialización, llevaron a políticos, urbanistas e ingenieros a soterrarlos; coincidiendo con el desarrollo de las tecnologías sanitarias modernas y el auge del tráfico rodado frente a la navegabilidad. Por último, la aportación analiza la actual propuesta municipal para recuperar las antiguas canalizaciones. Para ello, se discuten los objetivos del proyecto a escala urbana y metropolitana, junto al resto de problemáticas presentes en esta urbe del Norte de Italia.

\section{Palabras clave}

Canales; Infraestructura histórica; Navigli; Patrimonio urbano; Planeamiento urbanístico; Recuperación de usos.

\section{Abstract}

Milan has devoted tireless efforts to establish a hydraulic infrastructure as a connection to other cities, despite settling on a water layer, which naturally supplies it. Intending to bridge the distance towards the nearest rivers, an extensive system of navigable canals was built. So that, it earned the name Città dell'acqua. Paradoxically, the ideas to remove these anthropogenic waterworks arose from one of its earlier urban development plans, at the end of the 19th century. This article characterizes its hydrography and the so-called navigli, its medieval and modern waterworks, chronologically. The arguments that led politicians, urban planners and engineers to dispense with them after industrialization, coinciding with the first modern sanitary systems and the increase in road traffic against navigation, are exposed below. Based on this, the contribution discusses the current controversy regarding the municipal proposal to recover the old canal system. Along with other issues, the project objectives are reviewed both at urban and metropolitan scale.

Keywords

Canals; Functional rehabilitation; Historic infrastructure; Navigli; Urban heritage; Urban planning

Celia López-Bravo, clopez30@us.es. Arquitecta (2015), Máster en Arquitectura y Patrimonio Histórico (2017). Contratada Predoctoral Dpto. Historia, Teoría y Composición Arquitectónicas, Universidad de Sevilla. Premio Málaga Investigación (2019). Publicaciones recientes: Revista PH, 2019. Núm, 97; Constelaciones, 2019. Núm. 7; Touriscape: Turismo y Paisaje, Tirant lo Blanch 2019.

Eduardo Mosquera Adell, emosquera@us.es. Doctor arquitecto (1991), Premio Extraordinario de Doctorado. Catedrático Dpto. Historia, Teoría y Composición Arquitectónicas, Universidad de Sevilla. Publicaciones recientes: Sustainable Cities and Society. Vol. 54, March 2020; Constelaciones, 2019. Vol. 1. Núm. 7; EGA Expresión Gráfica Arquitectónica, Vol. 23, 32, 2018; revista PH, 95, 2018. 
[Fig. 1] Felice Poggi. Sección altimétrica del terreno y de las aguas del subsuelo según las líneas de máxima y mínima pendiente a la altura del Broletto (Piazza Mercanti), 1911. Fuente: Felice Poggi, Le foganture di Milano, 1911.

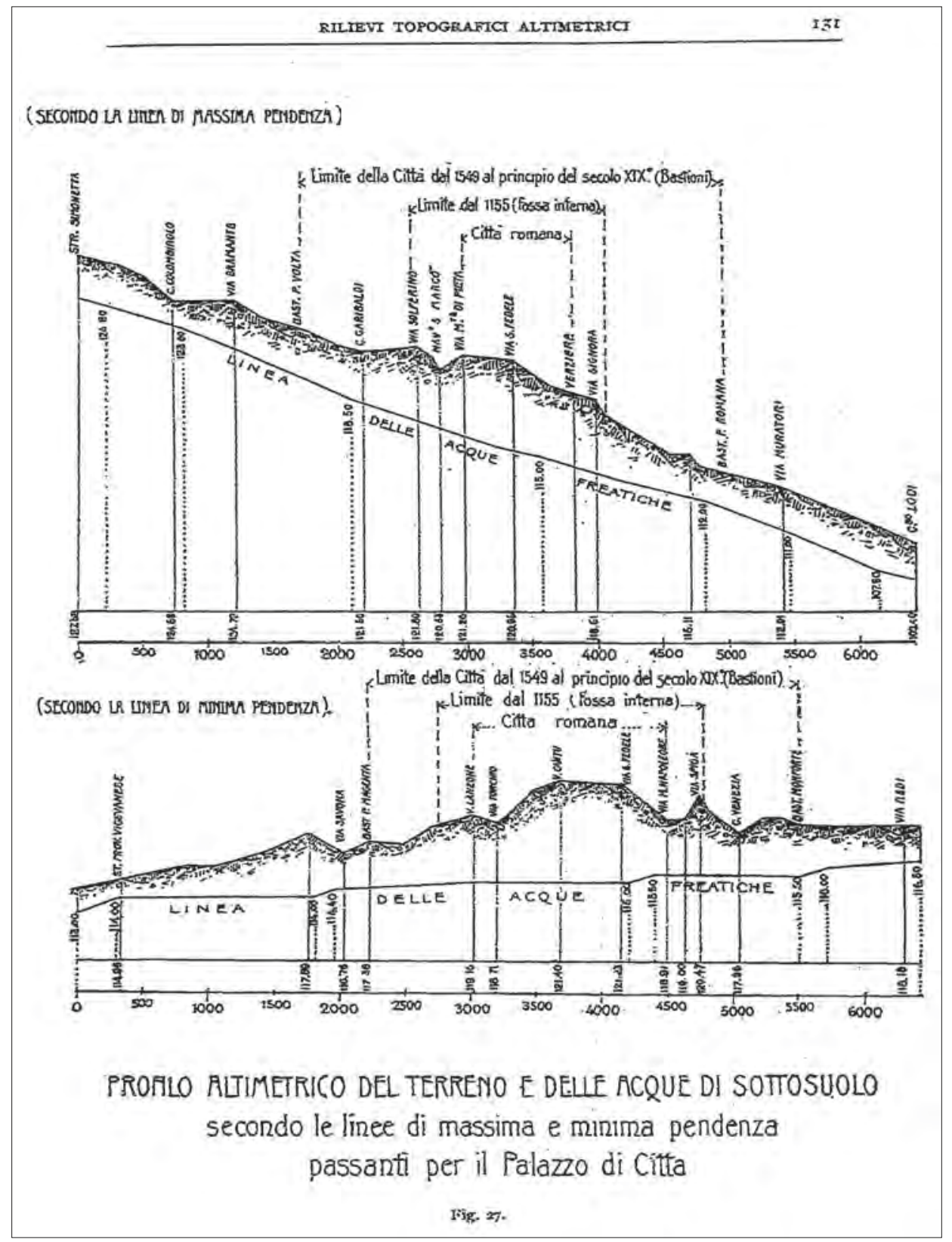

\section{Mediolani, una ciudad alejada de mares y ríos}

Las ciudades históricas pueden dividirse en aquellas que han evolucionado sobre la base de la defensa del agua y aquellas que han buscado el agua como método de subsistencia. En ambos casos, el agua y la defensa han supuesto los dos grandes criterios de organización urbana. Milán es un claro referente del segundo grupo, una ciudad que nació gracias a la tecnificación del agua hace más de un milenio.

En Milán, el agua canalizada ha mantenido a lo largo de su historia sus relaciones territoriales con el resto de Lombardía. Ha diseñado su trazado urbano, ha generado industrias y permitido el transporte de mercancías posibilitando la construcción de edificaciones monumentales, ha propiciado gran parte de su riqueza económica y, en consecuencia, ha modelado a su sociedad y su cultura. ${ }^{1}$

Es posible admitir que la región de Lombardía es la consecuencia de un continuo y persistente paisaje proyectado, determinado por las necesidades de la sociedad. Un pueblo que basó su economía en la agricultura desde su origen, actividad que aún pervive en un territorio marcado por la industrialización. Ambas actividades prosperaron gracias a su situación geográfica y a un constante proyecto de ingeniería emprendido en tiempos romanos que continúa aún presente.

La región lombarda se caracteriza por dividirse casi equitativamente, de Norte a Sur, en el área montañosa de los Alpes y la llanura Padana, esta última asentada sobre un manto hídrico que mantiene un alto nivel freático a temperatura constante [Fig. 1]. 


\section{ZARCH No. 15 | 2020}

\section{Procesos urbanos,}

dinámicas del agua

y cambio climático

Urban processes,

water dynamics and

climate change

\section{CELIA LÓPEZ-BRAVO}

ANTONELLA CONTIN

EDUARDO MOSQUERA ADELL

Milano Città d'Acqua, un debate actual

en torno a la recuperación

del patrimonio hidráulico

Milano Città d'Acqua, a current

discussion related to water

heritage recovery
2 Puntos de subida natural del agua a la superficie que permiten el riego mediante soluciones técnicas basadas en pendientes, evitando que los cultivos se hielen durante el invierno o se sequen durante el verano.

3 Gian Battista Bischetti y otros, Tutela e valorizzazione dei fontanili del territorio lombardo. Quaderni della ricerca (Milán: Università degli Studi di Milano, Facoltà di Agraria, 2012).

4 Bonvesin de la Riva, De magnalibus Mediolani (Milán: Bompiani, 1974).

5 Gianandrea Barreca, ed., New water anthropology (Milán: Domus, 2014).

6 Gian Luca Lapini, "Cenni sull'idrografia dell'area milanese", Storia di Milano, 2004, http://www.storiadimilano.it/citta/ milanotecnica/fognature/idrografia.htm (consultada el 5 de septiembre de 2019).

7 El Naviglio della Vettabbia (s. II. d.C.), Naviglio Grande (s. XII), Naviglio della Martesana (s. XV), Naviglio di Bereguardo (s. XV), Naviglio di Paderno (s. XVI) y Naviglio Pavese (s. XVI).

8 Canale Ticinello, Canale Vetra, Cavo Redefossi (s. XIV), Cavo Ticinello y Lambro Meridionale.

9 También denominada Fossa Interna o Naviglio interno, su recorrido coincide con el del foso defensivo de la muralla de la ciudad bajo la dominación española en el siglo XVI.

10 Giovanni Denti y otros, Milano: l'ambiente, il territorio, la città (Florencia: Alinea Editrice, 2014).
Al pie del área montañosa perviven aún grandes lagos de origen glaciar. Los beneficios hidrológicos y térmicos de esta condición geológica han sido históricamente conocidos y empleados en la agricultura a través de los llamados fontanili, ${ }^{2}$ actualmente protegidos por la administración medioambiental italiana y en activo en gran parte de la superficie agrícola lombarda. El empleo de estos resurgimientos naturales puede datarse en torno al primer milenio, gracias al estudio de la toponimia y los registros de propiedad históricos. ${ }^{3}$

Tal como expresa el nombre histórico de su capital, Mediolani ${ }^{4}$ o Terra di Mezzo, 5 Milán es una ciudad nacida en el centro de una vasta planicie, en el espacio intermedio entre importantes parejas de ríos, el Adda y el Ticino, el Olona y el Lambro, el Seveso y el Nirone. Sin embargo, la ciudad no se localiza a orillas de ninguno de ellos. Su leve topografía acusa dos ligeros valles, conocidos como bacini, que dirigen pequeñas corrientes y arroyos. Pero la necesidad agudiza el ingenio y, paradójicamente, el agua ha sentado sus bases y criterios de planificación a lo largo de sucesivas ordenaciones y crecimientos, hasta la llegada del automóvil. Como en el resto de la región, la relación de Milán con el agua es antigua, siempre consecuencia de la planificación y el proyecto. Canales, esclusas, muelles, dársenas e incluso puertos y pequeños lagos urbanos han conformado, hasta los primeros años del siglo XX, el paisaje urbano de esta ciudad en medio de la planicie.

En su área metropolitana, de origen galo-romano, los cursos naturales más importantes son los ríos Lambro, Olona y Seveso y los torrentes Bozzente, Garbogera, Lura, Merlata y Pudiga. ${ }^{6}$ Pero el agua, empleada para uso militar, navegación de mercancías y pasajeros, irrigación, consumo animal, lavaderos, fuerza motriz, alcantarillado y, posteriormente, uso industrial, dependía de construcciones artificiales.

Entre las formas del agua que han generado la ciudad se distinguen tres tipologías principales: los navigli o canales navegables, ${ }^{7}$ los canales no navegables ${ }^{8}$ y los diques, entre los que hoy perduran dos, la Darsena di Porta Ticinese (antiguo Laghetto di Sant'Eustorgio) y el Idroscalo di Milano, construido en los años treinta. Derivados de estos se conservan también arquitecturas insertas en la ciudad y sus barrios periféricos: las esclusas de la Incoronata (s. XV), Viarenna (s. XV), Fallata (s. XVI) y la Conchetta (s. XVI); algunos molinos de agua, como el Dorino (s. XVII) o el Vettabbia (s. XVII); y puentes, como el Ponte delle Gabelle.

\section{Los Navigli della Vettabbia, Grande, Pavese y della Martesana}

Este sistema artificial de aguas territoriales navegables que alcanzan la ciudad se materializa en una serie de canales o navigli construidos durante el periodo comprendido entre el siglo II d.C., con la construcción del Naviglio della Vettabbia de origen romano, y principios del siglo XIX, con la culminación del Naviglio Pavese [Fig. 2]. Entre los destacados anteriormente, los Navigli Grande, Martesana y Pavese han protagonizado la historia y determinado la morfología y el crecimiento radial de la ciudad, conectados mediante la Cerchia dei Navigli ${ }^{9}$ que envuelve la ciudad histórica. El Naviglio Grande inicia su construcción el siglo XII, mientras el Pavese conecta finalmente con el río Ticino a su paso por Pavía en 1819. Esto supone un recorrido de más de ochocientos años de historia y los convierte, en gran medida, en responsables de la prosperidad económica de esta ciudad. ${ }^{10}$

Sobre el origen de la Vettabbia, uno de los primeros elementos construidos en el sistema de aguas milanés, existen distintas hipótesis. La mayoría de ellas datan su creación en los últimos siglos del Imperio Romano. Este canal conecta escorrentías naturales existentes con tramos de canalización artificial y recorre mediante un trazado regular y rectilíneo el Sudeste de la ciudad. Desde la Piazza Vetra, a 


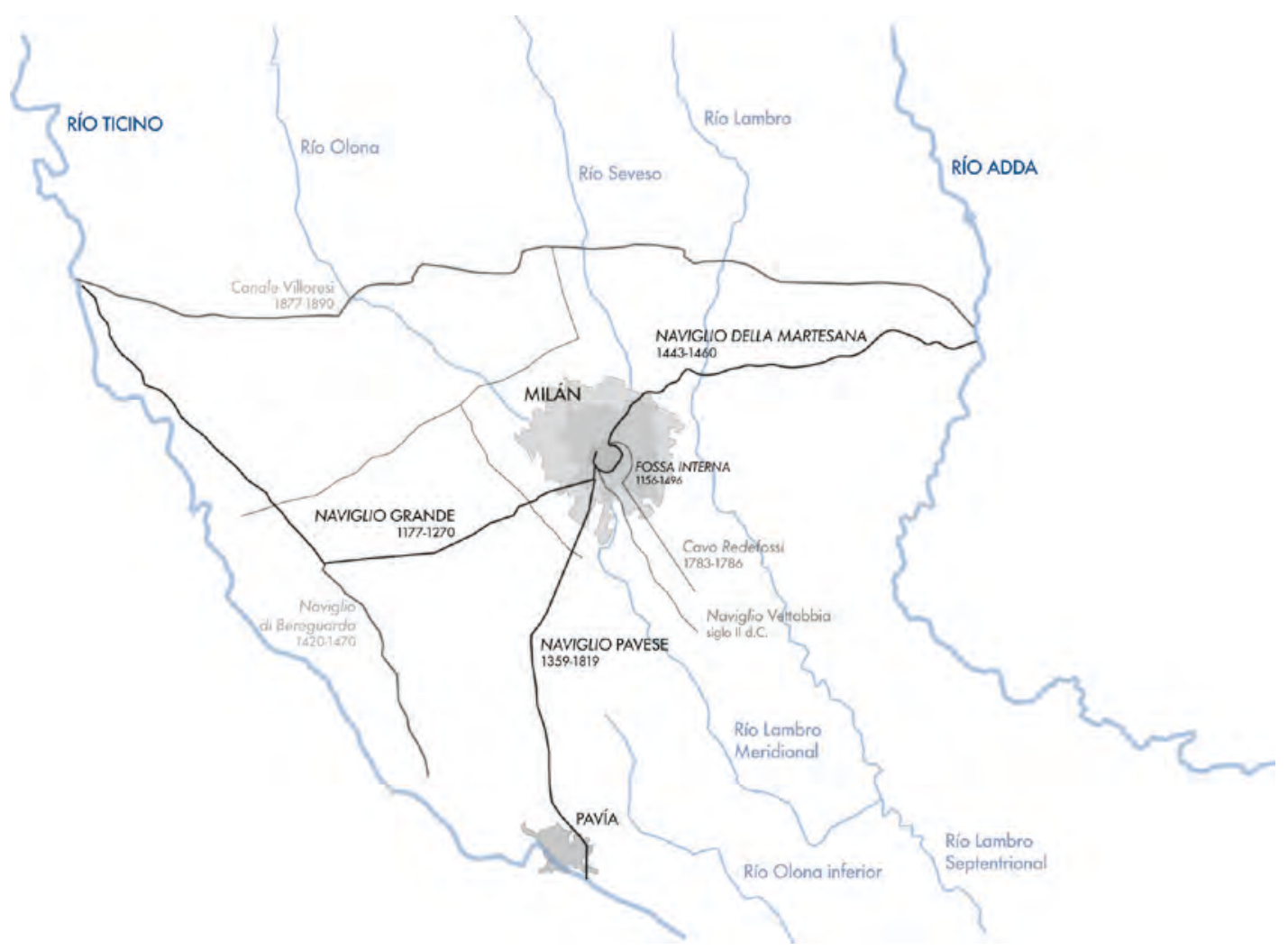

[Fig. 2] Celia López-Bravo. Esquema del sistema hídrico artificial de Milán y su entorno, 2020. Fuente: elaboración propia.
11 Marco Prusicki, "La Vettabbia, flumen mediolanensis", en Dalle marcite ai bionutrienti. Passato e futuro dell'utilizzo agricolo delle acque usate di Milano (Milán: Edizioni Angelo Guerini e Associati), 17-41.

12 Antonello Boatti y otros, ed., I nuovi navigli milanesi. Storia per il futuro (Santarcangelo di Romagna, Rimini: Maggioli, 2018). espaldas de la Basílica de San Lorenzo Maggiore, hacia el río Lambro. ${ }^{11}$ Como cita el profesor Prusicki, su designación medieval, Vitabilis, proviene de la palabra latina vehere, que hace referencia a la acción de transportar, de ahí su carácter navegable. A partir del siglo XI la fuerza motriz de estas aguas fue empleada en el funcionamiento de molinos, constituyendo en los siglos sucesivos la espina dorsal de una importante área agrícola donde se localizaron varios monasterios. De todos ellos, el principal fue la Abadía di Chiaravalle, un complejo cisterciense aún hoy en activo. La particular historia de este canal le hizo constituir durante siglos el conducto de alcantarillado a cielo abierto de la ciudad, que, gracias a un sistema de filtración eficiente, garantizaba un mayor rendimiento de la producción agrícola. Actualmente, parte de su trazado se encuentra oculto bajo el suelo urbano mientras el resto, desde la construcción en 2004 de la planta de tratamiento de aguas del Nosedo, forma parte del Parque Agrícola Urbano del Valle de la Vettabbia.

Proveniente del río Ticino, el Naviglio Grande alcanza Milán desde el Sur en la Darsena di Porta Ticinese, desde donde parten el Naviglio Pavese y varios canales secundarios. Construido entre los años 1177 y 1270, establece la conexión de unos 50 kilómetros de longitud entre Milán y la localidad de Lonate Pozzolo y la conecta con el Lago Maggiore. Es el único canal clasificado hoy como navegable, aunque su función principal es la de canal de riego.12

Al Norte y procedentes del río Adda, las aguas del Naviglio della Martesana entran en contacto con la ciudad de Milán a través de la Via Padova, hasta llegar a la Ilamada Cassina de'Pomm, una propiedad agrícola destinada históricamente al cultivo de frutas y miel, actualmente transformada en parque público. Una vez aquí, el canal circula de forma subterránea siguiendo la Via Melchiorre Gioia y desemboca en el Laghetto di San Marco, hoy subterráneo, a los pies de la iglesia del mismo nombre. Desde este punto las aguas son redirigidas al Cavo Redefossi y desembocan en el río Lambro. La Martesana es un canal de unos 38 kilómetros de recorrido, construido bajo la dominación de los Sforza en el breve periodo comprendido entre 1443 y 1460, navegable desde 1471. Su función histórica ha sido el riego de los campos, la producción de energía hidráulica en molinos durante la primera industrialización, el transporte y la conexión con el Lago di Como. 
Procesos urbanos,

dinámicas del agua

y cambio climático

Urban processes,

water dynamics and

climate change

\section{CELIA LÓPEZ-BRAVO}

ANTONELLA CONTIN

EDUARDO MOSQUERA ADELL

Milano Città d'Acqua, un debate actual

en torno a la recuperación

del patrimonio hidráulico

Milano Città d'Acqua, a current

discussion related to water

heritage recovery
La diferencia de nivel existente entre su localidad de partida, Trezzo sull'Adda, y el punto de llegada a Milán, supone unos 26 metros de desnivel que obligaron a la construcción de la Conca dell'Incoronata. Esta esclusa es hoy el único testigo del canal en el interior de la ciudad histórica. Fue construida en 1496 y los primeros diseños para su construcción, localizados en el Codice Atlantico, ${ }^{13}$ fueron realizados por Leonardo da Vinci.

El Naviglio Pavese, por su parte, aseguraba la conexión de la ciudad con el río Ticino a la altura de Pavía, a través un recorrido de 33 kilómetros de largo. Sin embargo, la diferencia topográfica implicó la construcción de doce esclusas que añadieron una gran dificultad a las obras. Estas comenzaron en 1359 y, tras su avance, se detuvieron en 1610 después de la construcción fallida de la denominada Conca Fallata. La continuación de los trabajos no se retomó hasta la entrada de las tropas de Napoleón en la ciudad en 1800, siendo finalmente culminados en 1819 gracias a la construcción en Pavía de la denominada Scala d'acqua. Hoy su uso principal es el regadío, aunque su salto de agua a la altura de la Fallata fue empleado a finales del siglo XIX y principios del siglo XX para la generación de energía en una pequeña y pionera central eléctrica. ${ }^{14}$

Existen innumerables referencias que aportan datos respecto a estas cuatro grandes estructuras lineales, si bien es cierto que muchas de ellas introducen errores y contradicciones. Este amplio patrimonio ha sido representado en numerosas cartografías históricas que representan una Milán invadida por el agua, pero a finales del siglo XIX todo cambió [Fig. 3].

\section{Felice Poggi, los proyectos de la rete fognaria y el acquedotto civico}

En la ciudad de los canales los problemas quedaron demostrados en 1866, cuando el ingeniero Emilio Bignami evidenció en una de sus publicaciones las graves condiciones higiénicas que presentaban los cursos de agua milaneses. ${ }^{15}$ Justo cuando, en un pacto territorio-industria, el transporte por agua alcanzó su máximo esplendor, se alzaron las primeras propuestas para cubrir los canales. Lo que puede parecer una contradicción, se debía a una nueva conciencia del agua urbana en el ámbito higiénico. ${ }^{16}$

Esto ocurrió en la mayoría de las grandes ciudades europeas en las que el desarrollo industrial supuso un rápido aumento de la población, agravando el problema sanitario ya presente y proliferando distintas epidemias. ${ }^{17}$ Según Maurizio Brown, la causa principal de la insalubridad de las aguas fue la alta contaminación de los cursos superficiales, que actuaron como colectores para la conducción de aguas residuales. ${ }^{18}$ Las infiltraciones de estas aguas sucias terminaron por contaminar además los pozos de suministro.

Este debate en torno a la supresión de los navigli, que será objeto del siguiente apartado, se vio acompañado por la planificación de otras dos infraestructuras determinantes. Además de los canales y los pozos existentes, las redes de alcantarillado y suministro de agua potable dispuestas a finales del siglo XIX constituyeron un intrincado patrimonio de escala metropolitana relativo al agua. A partir de ese momento, las conexiones antes visibles para los ciudadanos pasaron a localizarse en el subsuelo.

Estos dos nuevos sistemas restablecerían, capitaneados por la idea de modernidad, el orden, la limpieza y la salubridad, apoyando la percepción de obsolescencia que reinaba sobre los antiguos canales y colaborando en el desarrollo industrial de la región. ${ }^{19}$ Según los estudios realizados por el ingeniero Felice Poggi, durante la época imperial romana la ciudad contaba con un sistema de alcantarillado, con- 
[Fig. 3] Antonio Vallardi. Fragmento del plano hidrográfico de la ciudad de Milán con canales en activo (línea azul continua) y cubiertos (línea azul discontinua), 1888. Fuente: Biblioteca Nazionale Braidense. Disponible en: http:// milanocittadellescienze.it/it/mostre/carte-epiante/carte-e-piante-galleria/cartepiante_ img07/

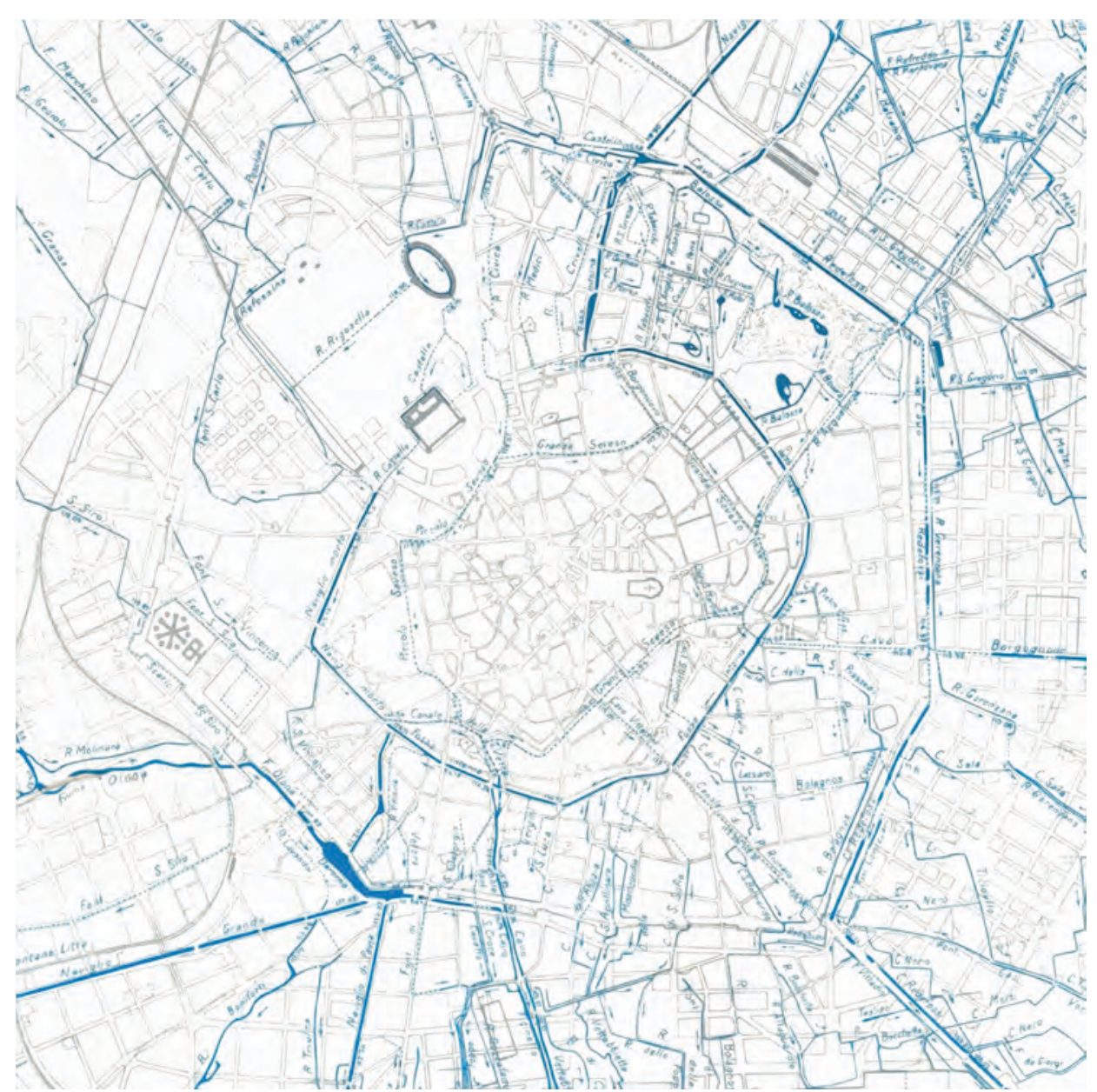

formado por conductos que recogían las aguas de las calles y las dirigían hacia el Lambro. ${ }^{20}$ Tras la caída del Imperio se produjo un largo periodo de decadencia y hasta los inicios del Renacimiento, no hubo tentativas de construir nuevas conducciones. Se construyeron entonces algunos conductos para la recogida de aguas pluviales, aunque de forma independiente y dirigidos hacia los antiguos canales; mientras las aguas fecales se depositaban en los llamados pozos negros. Con relación al abastecimiento, si el agua para riego y transporte había protagonizado grandes obras en la historia de la ciudad, el agua para consumo humano había hecho de su disponibilidad inmediata y su uso espontáneo un hábito hasta finales del siglo XIX. Por ello, el estrato hídrico subterráneo sobre el que se asienta la ciudad es considerado por muchos un río sumergido, ${ }^{21}$ cuyo caudal ha ido variando en función de las actividades que históricamente han liderado la economía y subsistencia de la zona. ${ }^{22}$

A diferencia de otras ciudades italianas, Milán nunca requirió de grandes estructuras para traer el agua potable a la ciudad, como el caso de Roma, dada la calidad, la abundancia y la proximidad del ya nombrado manto freático. Sin embargo, los pozos que suministraban agua a los milaneses hasta finales del siglo XIX, en la mayoría de los casos autoconstruidos, no superaban los 6 o 7 metros de profundidad y comenzaron a acumular excesivas filtraciones que provocaron la contaminación de sus aguas.

En 1880 el Ayuntamiento publicó un primer concurso para la construcción de un acueducto municipal que asegurase la llegada de agua para el consumo humano a la ciudad. Tras un segundo concurso en 1887, coincidiendo con un nuevo plan urbanístico, resultaron numerosas opciones de proyecto, siendo elegida la propuesta del ingeniero Felice Poggi. Poggi no planteó traer el agua de ríos o lagos, sino obtener y repartir el agua del subsuelo, más próxima y de excelente calidad. ${ }^{23}$ De esta forma se fueron excavando distintos pozos experimentales desde 1888 y
23 Vittorio Motta, L'acquedotto di Milano (Milán: Comune di Milano, 1989). 
[Fig. 4] Autor desc. Proyecto de depósito de aguas en el torreón Sur del Castello Sforzesco, 1906. Fuente: V. Motta, L'acquedotto di Milano, 1989.

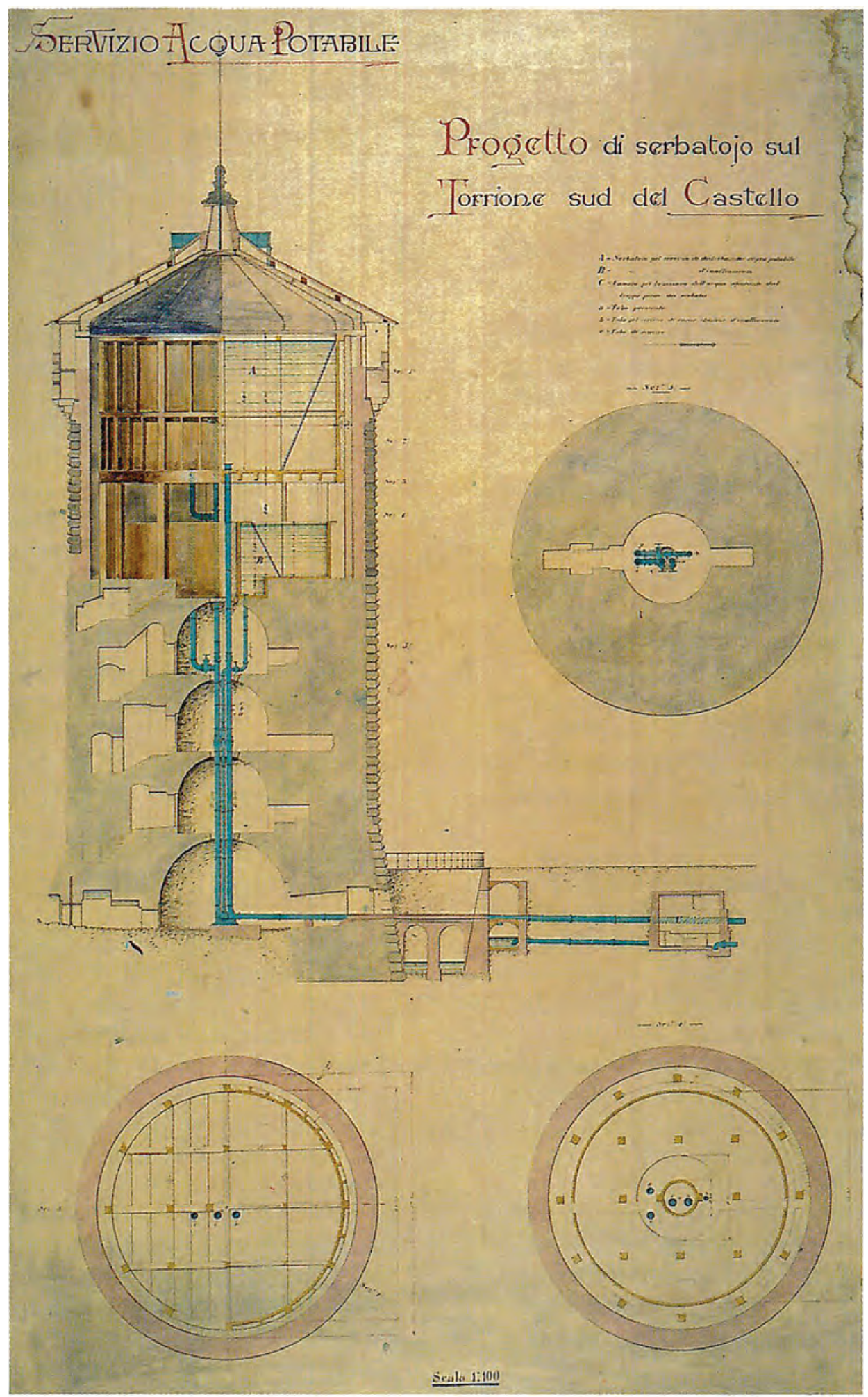

durante los años sucesivos, dando lugar a los primeros impianti, las primeras de las instalaciones de bombeo. Tras la construcción del primer ramal de distribución, el lugar elegido para la construcción de un depósito elevado en 1892 fue el torreón Este del Castello Sforzesco, coincidiendo con la restauración del complejo por Luca Beltrami, iniciada en 1893. Posteriormente, en 1904, se construyó un segundo depósito en el torreón Sur, empleando el entonces novedoso hormigón armado como material de construcción [Fig. 4].

En 1890, un año después de la aprobación del plan conocido como Piano Beruto, que constituía una oportunidad para garantizar el alcantarillado de las nuevas zonas planificadas, se aprueba el proyecto para el alcantarillado general de la ciudad, también bajo las órdenes del ingeniero Poggi. El proyecto, culminado en 1893, dividía la ciudad en zonas, cada una de las cuales era dirigida hacia un colector, estableciendo una primera regulación municipal en la materia. 


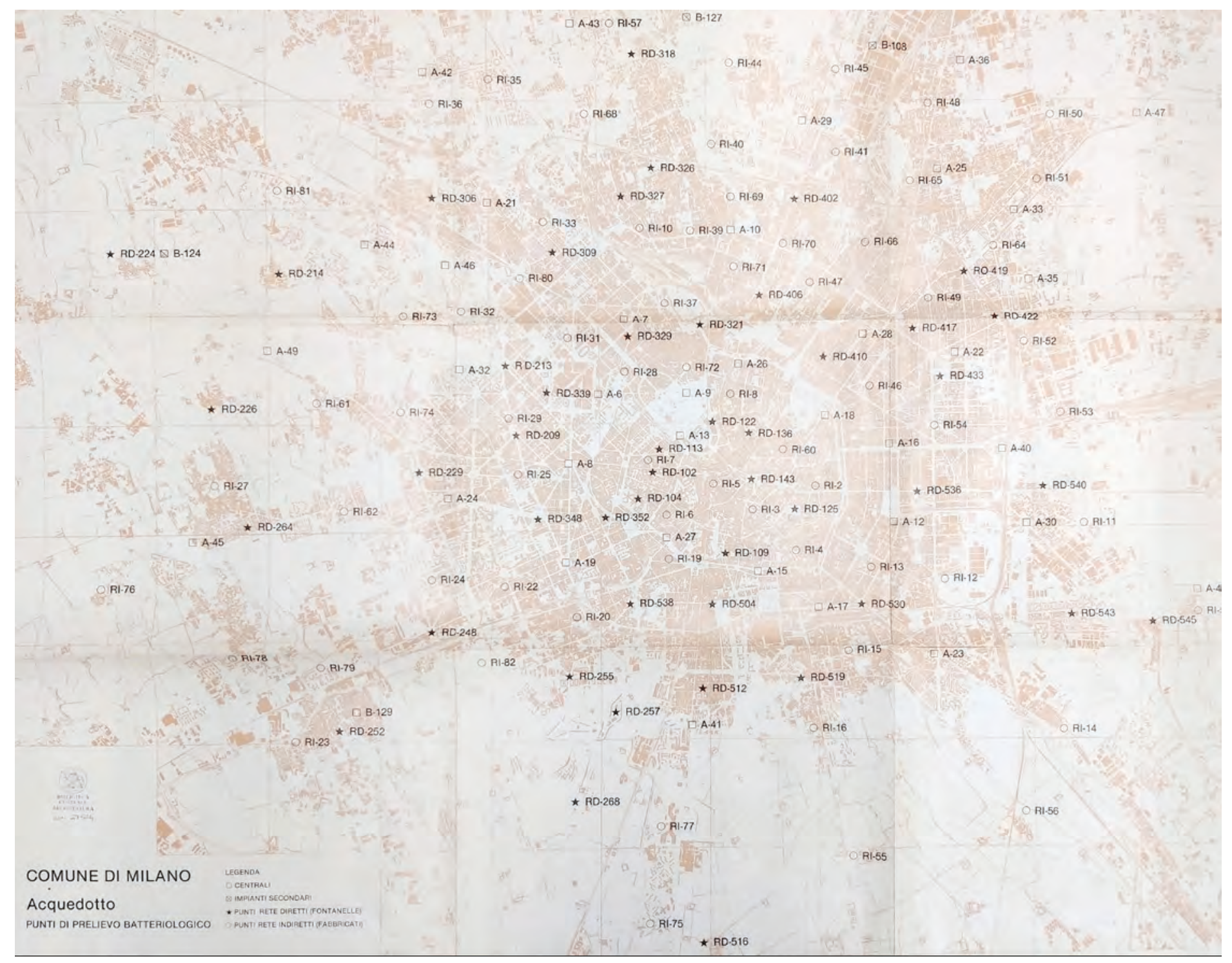

[Fig. 5] Comune di Milano. Puntos de extracción del acquedotto civico, 1988. Fuente: V. Motta, L'acquedotto di Milano, 1989.

24 Amerigo Belloni, L'acquedotto milanese: l'approvvigionamento idrico della città di Milano dal 1892 al 1951 (Milán: U. Hoepli, 1952).

25 La antigua Centrale Cenisio de 1906, hoy Centrale dell'acqua di Milano, fue reabierta al público como espacio expositivo y cultural en 2018.

26 Bianca Dendena, ed. Paesaggi d'acqua. Milano e dintorni. Utopie / 6 (Milán: Fondazione Giangiacomo Feltrinelli, 2018).

27 "Se supone que Isaura, ciudad de los mil pozos, surge sobre un profundo lago subterráneo. Dondequiera que los habitantes, excavando en la tierra largos agujeros verticales, han conseguido sacar agua, hasta alli y no más lejos se ha extendido la ciudad: su perímetro verdeante repite el de las orillas oscuras del lago sepulto, un paisaje invisible condiciona el visible [...]" Italo Calvino, Las ciudades invisibles. Editado por Aurora Bernárdez (Madrid: Siruela, 1994).

28 Fondazione Adolfo Pini, "Il Piano Beruto", Storie milanesi, http://www.storiemilanesi.org/ approfondimento/il-piano-beruto/ (consultada el 20 de noviembre de 2019).
En los años siguientes el crecimiento de la ciudad reclamó el aumento de puntos de aprovisionamiento hídrico. La construcción de los nuevos impianti iba incorporando avances técnicos, pasando de sistemas de vapor a sistemas eléctricos. En 1909, la ciudad contaba con 9 puntos de extracción y una red de distribución de 256 kilómetros y 8460 puntos de servicio. ${ }^{24}$ Las centrales configuraron un nuevo tipo edificatorio, que generó toda una colección de arquitecturas, muchas de ellas hoy abandonadas y otras recuperadas, ${ }^{25}$ defendidas en sus estudios por la profesora M. A. Breda. ${ }^{26}$ En la actualidad, decenas de impianti constituyen este sistema de pozos que, como plantea la profesora Breda, quizá inspiró a Italo Calvino en el proceso de creación de Isaura, una de sus ciudades invisibles. ${ }^{27}$ [Fig. 5].

\section{La planificación del Piano Beruto y la supresión de los navigli}

Como ya se ha adelantado, en los últimos veinte años del siglo XIX se introdujeron grandes cambios en la vida de la ciudad con el desarrollo de estas dos nuevas infraestructuras hidráulicas. Además, comenzó a debatirse cómo sería su futuro urbanístico. Ante la necesidad de establecer reglas y límites de crecimiento a una ciudad de boyante economía, nació su primer plan de ordenación. El llamado Piano Beruto, iniciado en 1884, fijaba entre sus objetivos: dar respuesta a la creciente necesidad de vivienda, ordenar el crecimiento producido a partir de la Mura Spagnole, proteger el área que rodeaba el Castello Sforzesco y planificar la, progresivamente ascendente, periferia industrial. ${ }^{28}$ 
Procesos urbanos,

dinámicas del agua

y cambio climático

Urban processes,

water dynamics and

climate change

\section{CELIA LÓPEZ-BRAVO}

\section{ANTONELLA CONTIN}

EDUARDO MOSQUERA ADELL

Milano Città d'Acqua, un debate actual

en torno a la recuperación

del patrimonio hidráulico

\section{Milano Città d'Acqua, a current}

discussion related to water

heritage recovery
[Fig. 6] Cesare Beruto. Proyecto de plan regulador de la ciudad de Milán, 1884. Fuente: Biblioteca virtuale della grafica e dell'illustrazione libraria del Comune di Milano. Disponible en: http://graficheincomune. comune.milano.it
29 Giuseppe Codara, I navigli della vecchia Milano: passato, presente e futuro (Milán: Virgilio, 1977).

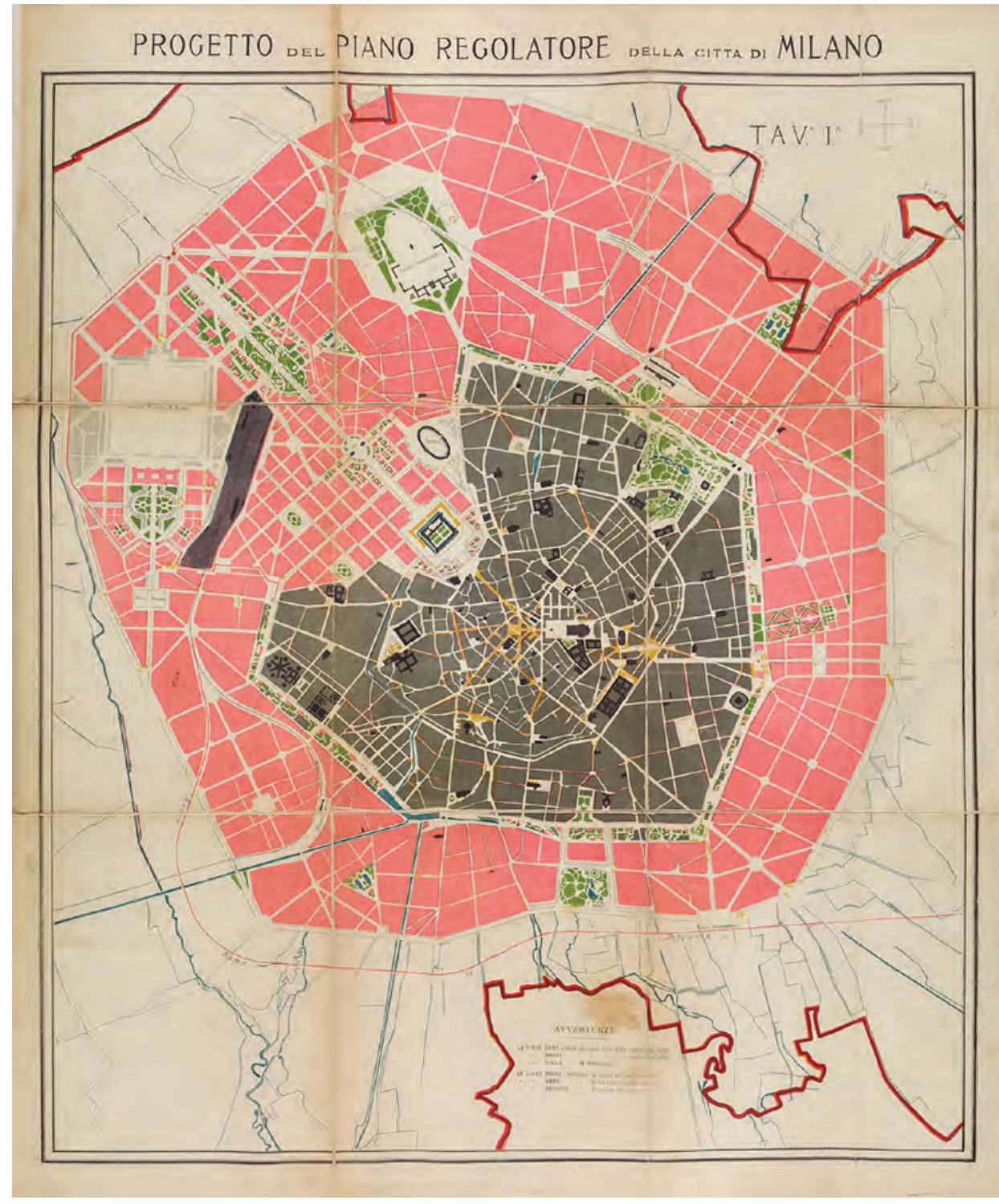

El plan preveía la construcción de dos avenidas concéntricas, una mediante el derribo de la muralla construida durante el periodo de dominación española (s. SVI) y otra de nueva creación, que delimitaba la expansión máxima prevista para la ciudad [Fig. 6]. Esto generaba un modelo de doble anillo, fuertemente influenciado por el vienés de la Ringstrasse. A este se adaptaba una malla de grandes manzanas ordenadas mediante calles y plazas distribuidas regularmente, cuya dimensión permitía la construcción de amplios jardines en el interior de los edificios. La corona de crecimiento de la ciudad era atravesada por grandes ejes, que convergían en el centro. Uno de ellos dio lugar a la apertura de la Via Dante, que conectó el Castello Sforzesco y el Duomo, y a la creación del Parco Sempione.

En paralelo a la reforma morfológica, la definición de la movilidad y las nuevas redes de ferrocarril, el plan apostaba por la ordenación de los sistemas de abastecimiento y canalización de aguas que han sido objeto del apartado precedente; además, atajaba drásticamente el problema higiénico-sanitario antes contemplado, mediante la cobertura de los principales cursos de agua de la ciudad. Si bien se trataba de solucionar un problema higiénico, las propuestas datadas en estos años planteaban la construcción de un canal de mayor sección destinado al transporte por agua en sustitución de la navegación en la Fossa Interna, ${ }^{29}$ alejado del centro urbano. Sin embargo, estas propuestas nunca llegaron a materializarse, debido a los elevados costes de ejecución y dificultad de las obras [Fig. 7]. 


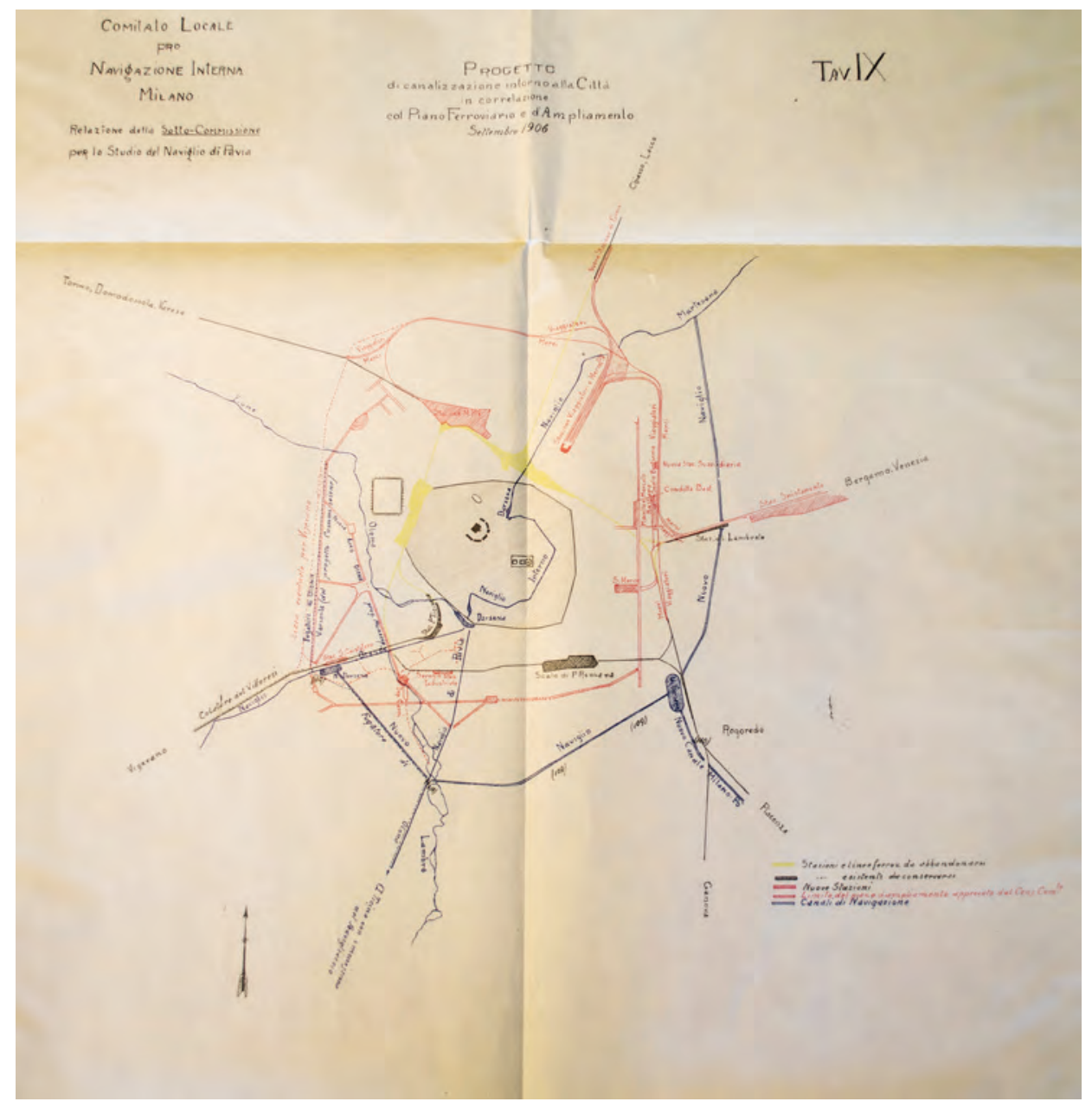

[Fig. 7] Comitato locale pro navigazione interna. Proyecto de canalización en torno a la ciudad de Milán en correlación con el Plano Ferroviario y de Ampliación, 1906. Fuente: Biblioteca Storica Politecnico di Milano.
El Piano Beruto fue aprobado definitivamente en 1889 y, con la intención de iniciar el saneamiento del sistema, la Fossa Interna fue revestida de hormigón y sometida a un ciclo de limpieza semestral que mejoraba notablemente las condiciones del agua y limitaba las filtraciones. En paralelo, los nuevos sistemas de alcantarillado y suministro de agua potable fueron estudiados y proyectados según las ideas del ingeniero Felice Poggi. La navegación continuó y tan solo dos pequeños tramos de navigli fueron cubiertos y canalizados mediante tuberías de hormigón durante esos años.

Pasaron varias décadas hasta que la idea de suprimir los canales internos volvió a resurgir. En 1928, bajo unas condiciones políticas distintas, fue aprobada la propuesta definitiva. Ante el éxito de las medidas de limpieza y el funcionamiento de la nueva red de alcantarillado, Brown sostiene la idea de que las razones que motivaron la propuesta definitiva de supresión de los canales entonces, pese a justificarse en motivos higiénico-sanitarios, no fueron sino la materialización de ideales urbanísticos. Entre ellas, la creación de un triple anillo rodado-ferroviario, la conexión del centro urbano supuestamente aislado por los navigli y, principalmente, la revalorización de una amplia superficie de suelo para ser destinada a nuevos inmuebles. Prueba de ello es la existencia de un Comitato pro-copertura, un comité de ingenieros y propietarios de inmuebles creado en 1925, que promovió la aprobación del proyecto. Esta propuesta concluyente también incluía la construcción de un nuevo canal concéntrico externo al área urbana; quizá, como afirma también el ingeniero Brown, a modo de aliciente para conseguir la aprobación del proyecto, a sabiendas de la imposibilidad de su construcción en aquel momento. Las obras, llevadas a cabo entre 1929 y 1930, respondían a la necesidad de rápida ejecución y se limitaron a cubrir los canales y construir sobre esta cobertura la respectiva vía rodada. 


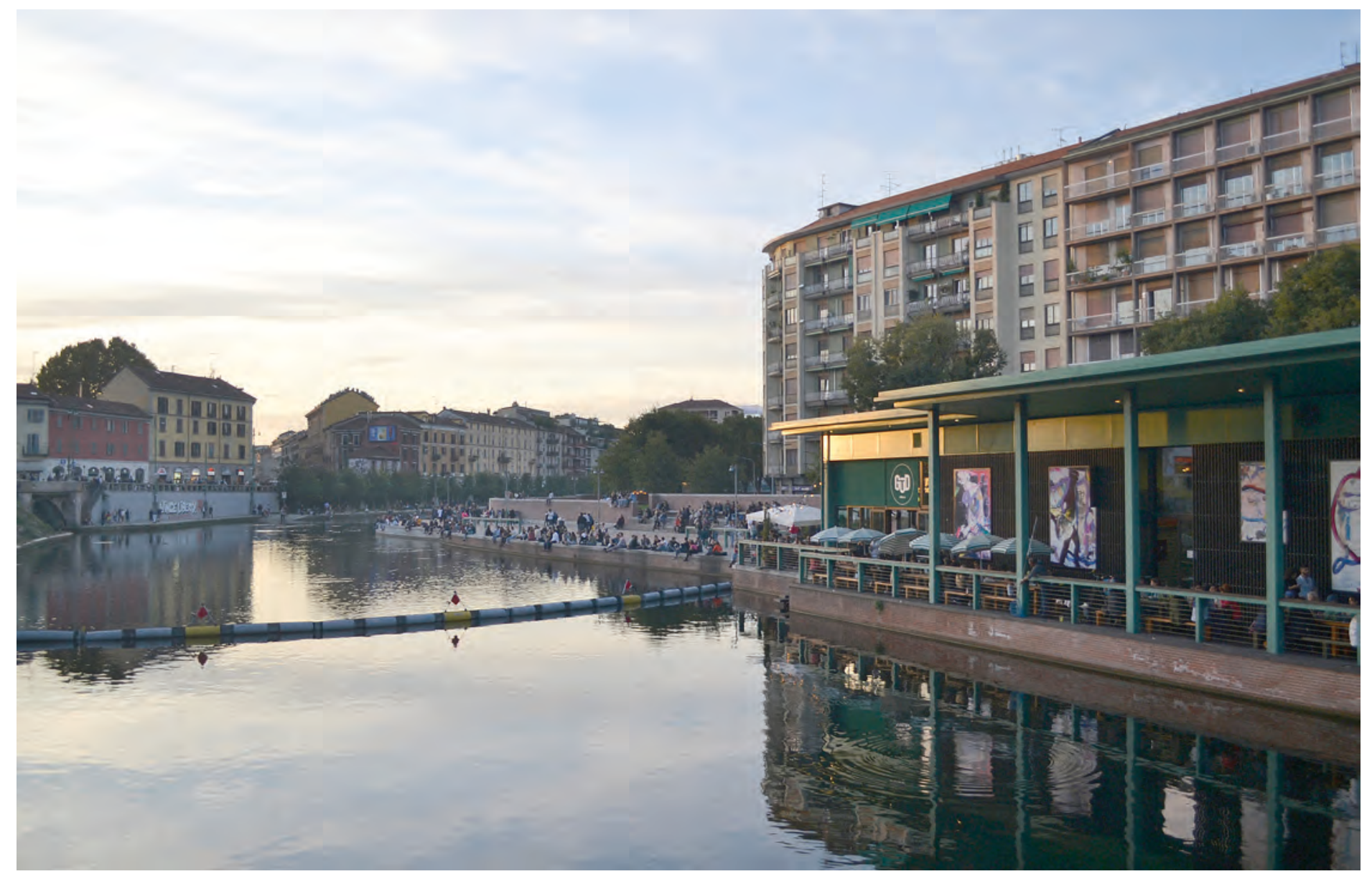

[Fig. 8] Celia López-Bravo Fotografía de la Darsena di Porta Ticinese recuperada, 2019. Fuente: elaboración propia.
30 Ippolito Ferrario y otros, Alla scoperta di Milano sotterranea (Milán: Newton Compton Editori, 2018).
En pleno siglo XX, bajo el régimen de Mussolini, Milán cambió canales por carreteras. El trazado urbano dejó de vincularse al uso del agua en superficie, enterrando gran parte de un patrimonio técnico y cultural y cubriendo con calzadas toda una conciencia histórica de organización geográfica, económica, ingenieril y cultural.

Los hallazgos arqueológicos hacen pensar que el agua es el hilo conductor de la historia comercial de Milán, justificando incluso la presencia de un puerto conectado con el Po hace más de 2000 años. ${ }^{30}$ Además, su estructura territorial atravesada por caminos de agua, en continua evolución desde el siglo XII, no se completa finalmente hasta el siglo XIX, con la culminación del Naviglio Pavese. Sin embargo, el avance de nuevos modos de transporte, el crecimiento de la ciudad y el poder económico del mercado inmobiliario no admitieron convivir con los antiguos sistemas territoriales, como evidencia este capítulo de su historia, comprendido entre los años treinta y setenta del pasado siglo XX.

La acción de determinadas políticas urbanas y la carencia de otras de carácter ambiental y patrimonial, junto a la priorización del transporte terrestre en la historia reciente, han llevado a que hoy, dentro del área metropolitana de Milán, solo una pequeña parte de los Navigli Grande, Pavese y Martesana se encuentre al descubierto, aunque sin navegación. El resto, fluyen bajo la superficie o han desaparecido por completo, como el Naviglio Vallone (s. XV) y la Cerchia dei Navigli (s. XII).

\section{El Proyecto Navigli y la reapertura de la Fossa Interna}

En el año 2015, bajo el lema "alimentar el planeta, la energía para la vida", tiene lugar la Exposición Universal de Milán. Su sede, un reclamo hacia nuevos modos de energía y distribución, fue proyectada por los arquitectos Herzog y de Meuron y denominada Expo Village. El proyecto ideaba un gran terreno agrícola-expositivo, rodeado por canales del siglo XXI, las llamadas Vie d'acqua, procedentes del Canale Villoresi. Canales que, además de regar esta área de la Exposición, generarían 

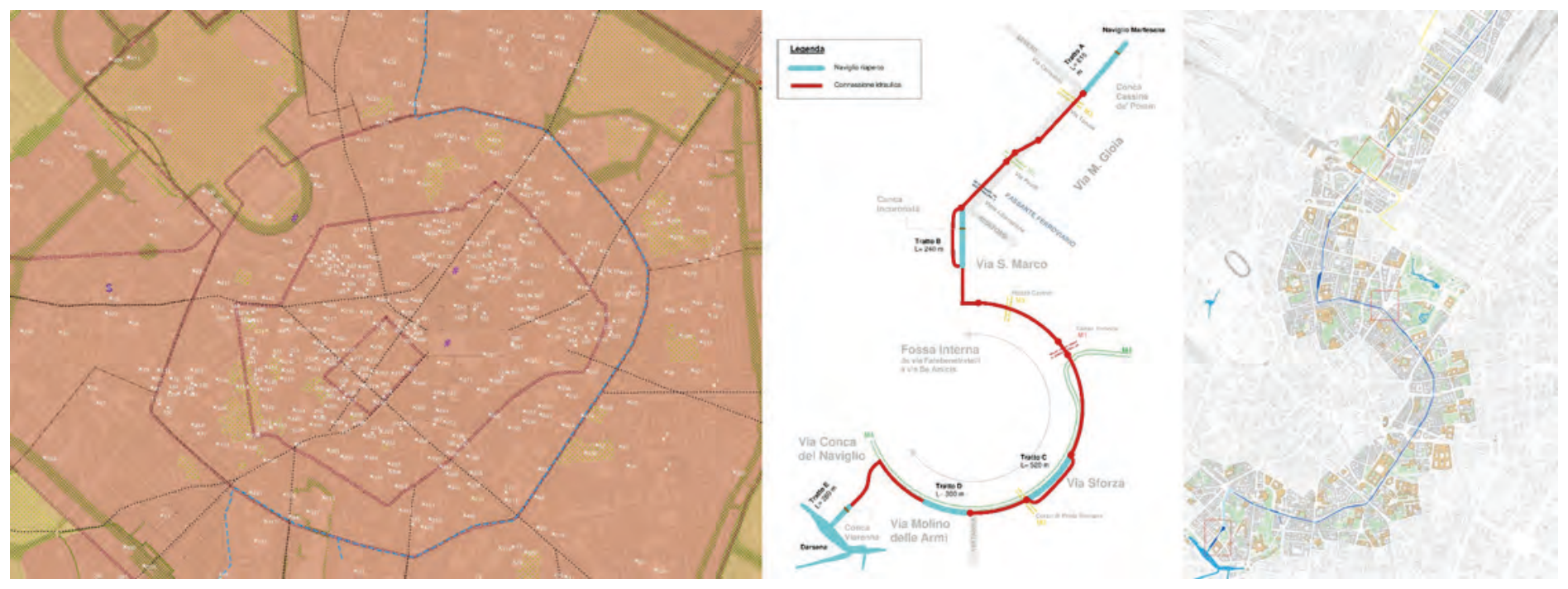

[Fig. 9] Comune di Milano. Fragmento de la Carta de Paesaggio y propuestas inicial y final para el trazado de la futura reapertura de los canales, 2020. Fuente: Piano di Governo del Territorio Milano 2030 y "Progetto Navigli". Disponibles en: http://allegati.comune.milano. it/territorio/PGT_BURL/1_DP/4_DP_D02_ Carta_paesaggio.pdf https://progettonavigli. comune.milano.it

31 Empio Malara, I/ naviglio di Milano (Milán: Hoepli, 2012).

32 Edoardo Guazonni, "La Darsena di Milano" http://www.edoardoguazzoni.com/la-darsenadi-milano (consultada el 8 de enero de 2020).

33 Antonello Boatti, coord., "Studio di fattibilità per la riapertura dei navigli milanesi nell'ambito della riattivazione del sistema complessivo dei navigli e della sua navigabilità", https:// progettonavigli.comune.milano.it/materiali/ progetto-di-fattibilita/ (consultada el 5 de septiembre de 2019).

34 Comune di Milano y MM Spa, "Progetto Navigli”, https://progettonavigli.comune.milano. it (consultada el 20 de marzo de 2019).

35 Comune di Milano, "Piano di governo del Territorio Milano 2030 (PGT)", https://www. comune.milano.it/aree-tematiche/urbanisticaed-edilizia/pgt-approvato-e-vigentemilano-2030 (consultada el 8 de mayo de 2020).

36 Comune di Milano y MM Spa, "Progetto Navigli, dossier di progetto", https:// progettonavigli.comune.milano.it/incontripubblici/dossier-di-progetto/ (consultada el 20 de marzo de 2019). un parque periurbano al Noroeste, conectado con el Naviglio Grande al Sur de la ciudad. Un ambicioso proyecto que quedó inconcluso, que fue objetivo de numerosas protestas ciudadanas y del que, finalmente, solo se realiza el área expositiva y una intervención urbana, la reapertura de la Darsena de Porta Ticinese.

La Darsena, en la que aún pueden verse algunos pescadores a diario, se encontraba inactiva desde 1975. ${ }^{31}$ Sin embargo, su reapertura supuso la creación de un gran espacio público al Sur de la ciudad, en el punto donde se encuentran los Navigli Grande y Pavese, descongestionando el área histórica [Fig. 8].

El proyecto se completó gracias a distintos elementos que dieron sentido a este nuevo espacio desde el punto de vista contemporáneo: áreas de paseo y esparcimiento, un jardín público, un nuevo mercado comunal, una pasarela de cruce, la recuperación de la explanada y la rehabilitación de la propia Porta Ticinese. ${ }^{32}$

A raíz de esta recuperación, políticos y técnicos apoyados por el trabajo de historiadores, arquitectos, urbanistas e ingenieros, han planteado en los últimos años la posibilidad de reabrir los fragmentos aún existentes de los principales canales urbanos. Tras varias tentativas, el denominado Progetto Navigli, publicado en 2018 por el Ayuntamiento y la empresa pública Metropolitana Milanese, parece cada vez más real. ${ }^{33}$ En el momento de redacción de este artículo, el proyecto se encuentra en fase de debate público abierto ${ }^{34}$ y la propuesta forma parte de la actual Carta del Paesaggio, publicada en el Piano di Governo del Territorio 2030 (PGT) ${ }^{35}$ recientemente aprobado [Fig. 9].

Su objetivo principal es recuperar la vía navegable que bordeaba la ciudad histórica, reabriendo la Fossa Interna y conectando la Darsena di Porta Ticinese, al Sur, con el Naviglio Martesana a la altura del Laghetto di San Marco, al Norte. Como puede observarse en la figura 9, con una longitud de 7,7 kilómetros y dada la complejidad técnica y económica que implica, la fase inicial plantea la reconexión en diez tramos interconectados a través de una gran tubería subterránea, ubicando en un primer momento cinco zonas descubiertas de 850, 230, 410, 300 y 260 metros respectivamente. La previsión es la continuidad de la movilidad navegable, aunque inicialmente los tramos se plantean inconexos y no se define la sección de los tramos de conexión subterránea de las aguas. Las zonas reabiertas son posibles gracias a la reducción del espacio dedicado a los vehículos, permitiendo además el ensanchamiento de las aceras y la creación de carriles para bicicletas. ${ }^{36}$

Las intenciones de esta propuesta a escala urbana, tras una primera fase de elementos aislados, casan con las de un plan metropolitano, la Rete Ecologica Comunale di Milano 2030 (REC) recogida también en el actual PGT [Fig. 10]. Conscientes 


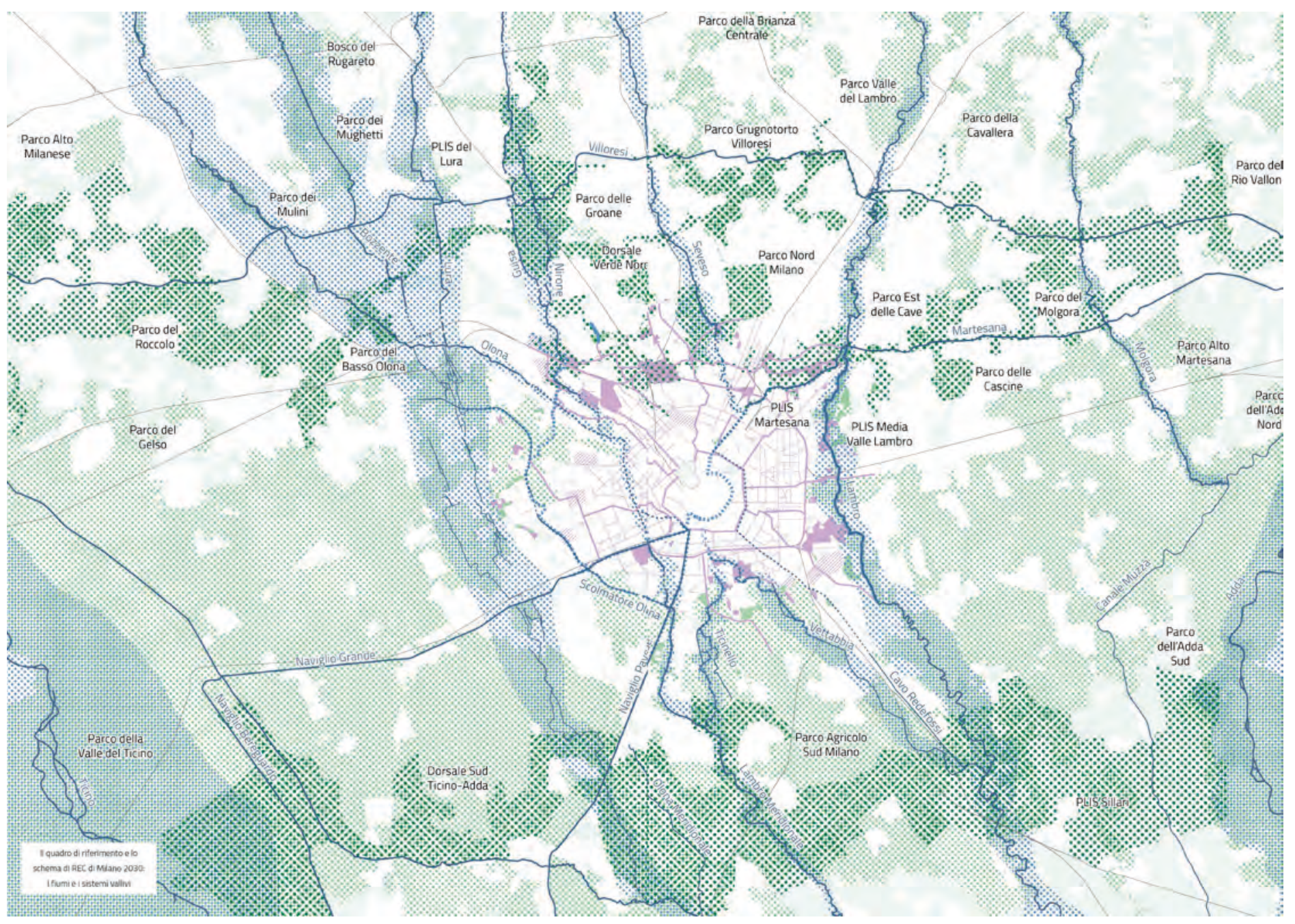

Figura 10. Comune di Milano. Esquema de la Rete Ecologica Comunale 2030 (REC), 2020. Fuente: Piano di Governo del Territorio Milano 2030. Disponible en: https://www.comune. milano.it/aree-tematiche/urbanistica-ededilizia/pgt-approvato-e-vigente-milano-2030 de la existencia y necesidad de conservación a nivel regional de dos grandes redes infraestructurales, las llamadas "verdes" y "azules", la REC plantea una serie de proyectos que definen a nivel estratégico un área de alta calidad agrícola y ambiental. Se centra en la conexión de los parques existentes y el incremento de esta área verde con veinte nuevos parques. En la carrera por la creación de un parque agrícola a escala metropolitana, su principal motor es la conectividad. Sin embargo, la supresión en el siglo XX de los antiguos canales dentro del núcleo de Milán impide la conexión de esta red a través del tejido urbano.

\section{Conclusiones: debate, nostalgia y complejidad bajo las calles}

Existen ejemplos de canales, la mayoría de ellos decimonónicos, que han sobrevivido al crecimiento de grandes ciudades europeas como París (Canal Saint-Martin, 1825) o Berlín (Landwehrkanal, 1845). Hoy, estas infraestructuras evolucionadas constituyen escenarios muy vivos que atienden a las necesidades actuales de sus habitantes, pese a haber perdido su función primitiva.

Otros casos han sido recuperados gracias a la labor de la legislación europea que, desde finales del siglo XX, ha impulsado la creación de infraestructuras verdes y azules, exitosamente aplicadas en ámbitos muy distintos. Algunas de ellas, a escala urbana, han surgido asociadas a la recuperación de infraestructuras urbanas obsoletas, como el pionero Coulée verte René-Dumont en París, la High Line de Nueva York, el Parque Cheonggyecheon en Seúl o el reciente Seoul Skygarden, en la misma ciudad coreana. A escala metropolitana, la mayor parte estas infraestructuras se encuentran ligadas a cursos fluviales, como el Parque del Turia en Valencia, el Parque Madrid Río o el Valle Trenzado del Vinalopó en Elche, entre los más conocidos ejemplos españoles. Otros modelos, en ciudades como Zaragoza o 
Vitoria, enlazan espacios naturales inconexos a través de los denominados Anillos Verdes. En el caso de Vitoria, articulado hace más de 25 años, el plan ha llevado a la recuperación de espacios industriales degradados, solucionando también problemas hidrológicos. En la capital aragonesa, la ruta conecta parques, cursos fluviales, zonas naturales y el paseo del antiguo Canal Imperial de Aragón a su paso por el Sur de la ciudad.

En el caso de Milán, si la conexión paisajística y ambiental que propone la REC cuenta con objetivos realistas a nivel regional de componente hidrológica, agrícola, térmica y funcional, a nivel urbano la reapertura de los canales genera cierta polaridad entre los expertos. La revisión del Dossier de Proyecto plantea al lector interrogantes relativos a su pulcra linealidad. En él, no se reconoce una traducción de los objetivos de la REC a esta escala. No aparecen alusiones a los jardines y parques existentes, ni se prevé la puesta en valor de espacios públicos y elementos patrimoniales ligados a los navigli o al acquedotto civico. Tampoco se reconoce un recorrido ciclista continuo más allá de los tramos recuperados de entre 200 y 900 metros de longitud, en una ciudad considerablemente llana con altos niveles de contaminación y que, hasta el momento, carece de suficientes carriles bici. ${ }^{37}$

Milán, como muchas otras ciudades históricas, ha sido víctima en su proceso de crecimiento de una cierta homogeneización. En este caso, su desarrollo ha afectado a uno de los elementos identitarios de su morfología urbana radial, toda una infraestructura hidrológica artificial. Sin embargo, ¿no es el agua en Lombardía un sistema de matriz geográfica?, ¿no ha estado siempre conectada a la producción agrícola, energética y, en definitiva, industrial?, ¿admiten las ciudades una vuelta al pasado literal? Cabe discutir si, en su actual proyecto por revertir el proceso de estandarización sufrido, no está sino abrazando paradójicamente conceptos con los que hace más de veinte años Rem Koolhaas definía la llamada "Ciudad Genérica". ${ }^{38}$ En su conocido ensayo, Koolhaas parece advertir, "cuanto más se abusa de la historia menos significativa se vuelve".

Aunque son ya muy pocos los milaneses que conocieron en vida una ciudad plagada de canales y pequeños lagos en lugar de plazas y avenidas, es evidente que la impronta territorial y social de las infraestructuras atiende a unidades de tiempo histórico ${ }^{39}$ y son muchas las publicaciones y portales web que recogen testimonios de este pasado. Pero la controversia se encuentra en cómo afectará la reapertura a nivel inmobiliario y fundamentalmente turístico, en una ciudad cuyo centro histórico se encuentra sobrepasado por este fenómeno. ${ }^{40}$ También existe el riesgo de concluir en un plan inacabado en el que no se produzca finalmente la navegabilidad de los canales, una variable que determina por completo el proyecto. Otro factor cuestionable es si, a nivel urbano, supone una verdadera mejora ambiental.

37 Luca Misculin, "Il Piano di Milano per favorire I'uso delle bici", Il Post, 29 de abril de 2020. https://www.ilpost.it/2020/04/29/milano-pisteciclabili-coronavirus/ (consultada el 23 de mayo de 2020).

38 Rem Koolhaas, Rem Koolhaas, acerca de la ciudad (Barcelona: Gustavo Gili, 2014)

39 Paul N. Edwards, "Infrastructure and modernity: force, time, and social organization in the history of sociotechnical systems", Modernity and technology 1(2003): 185-226. https://doi.org/0262633108

40 Comune di Milano, "Turismo. Nel 2019 sfiorati 11 milioni di visitatori”, Ufficio Stampa, 2020, https://www.comune.milano.it/-/turismo.-nel2019-sfiorati-11-milioni-di-visitatori (consultada el 20 de mayo de 2020).
Quizá Milán deba valorar cuáles son sus actuales necesidades frente a la reapertura de una vía acuática obsoleta, pues esta infraestructura ahora arqueológica, debe encontrar una razón estratégica para su conservación de manera sostenible. Es posible que aquello que los navigli supusieron en su día para la ciudad hoy pueda traducirse en un nuevo pacto energía-territorio para la reactivación de áreas sensibles, que colabore en la creación de energías alternativas y enmarque no a la ciudad histórica, sino a la contemporánea, en consonancia con el Naviglio della Vettabbia.

Si bien la viabilidad técnica del proyecto es un factor determinante, debe ser también estudiada su viabilidad funcional, cultural, patrimonial y -en definitiva- urbana, atendiendo a los requerimientos de la ciudad actual y futura. De otro modo, pese al gran potencial que pueda suponer crear un nuevo anillo de tal dimensión, podría consolidarse como una infraestructura nostálgica, diseñada únicamente para los visitantes o la rememoración, en contradicción con su origen utilitario. 
ZARCH No. 15 | 2020

Procesos urbanos,

dinámicas del agua

y cambio climático

Urban processes,

water dynamics and

climate change

\section{CELIA LÓPEZ-BRAVO}

ANTONELLA CONTIN

EDUARDO MOSQUERA ADELL

Milano Città d'Acqua, un debate actual

en torno a la recuperación

del patrimonio hidráulico

Milano Città d'Acqua, a current

discussion related to water

heritage recovery

\section{Bibliografía}

Airoldi, Ricardo y Casati, Pompeo. 1989. Le falde idriche del sottosuolo di Milano. Milán: Comune di Milano.

Arthurs, Joshua. 2013. Excavating modernity: the Roman past in fascist Italy. Nueva York: Cornell University Press. https://doi.org/10.1111/hisn.12030_49.

Barreca, Gianandrea, ed. 2014. New water anthropology. Milán: Domus.

Belloni, Amerigo. 1952. L'acquedotto milanese: l'approvvigionamento idrico della città di Milano dal 1892 al 1951 . Milán: U. Hoepli.

Bigatti, Giorgio. 2000. La città operosa: Milano nell’Ottocento. Milán: FrancoAngeli.

Bischetti, Gian Battista; Fumagalli, Natalia; Piantanida,Vittoria y Senes, Giulio. 2012. Tutela e vaIorizzazione dei Fontanili del territorio lombardo. Quaderni della ricerca. Università degli Studi di Milano, Facoltà Di Agraria. Vol. 144

Boatti, Antonello. 2003. "Milano ri-trova l'acqua e la sua storia. Gli elementi naturali e le risorse idriche come nuovi valori della qualità urbana nella metropoli." Ri-vista ricerche per la progettazione del paesaggio 1 (0): 63-85.

., coord. "Studio di fattibilità per la riapertura dei navigli milanesi nell'ambito della riattivazione del sistema complessivo dei navigli e della sua navigabilità." https://progettonavigli.comune.milano.it/materiali/progetto-di-fattibilita/ (consultada el 5 de septiembre de 2019).

Boatti, Antonello y Prusicki, Marco, eds. 2018. I nuovi navigli milanesi. Storia per il futuro. Santarcangelo di Romagna, Rimini: Maggioli.

Breda, Maria Antonietta, Brown, Maurizio y Redondi, Pietro, eds. 2016. L'oro di Milano. Usi agricole e sociali delle acque milanesi. Milán: Anthelios Edizioni.

Breda, Maria Antonietta y Padovan, Gianluca. 2018. Archeologia dell'acqua potabile a Milano. Hypogean Archaeology 10. Oxford: BAR Publishing.

Brown, Maurizio. "La soppressione del Naviglio Interno di Milano." Milano città delle scienze. 2018. http://milanocittadellescienze.it/wp-content/uploads/180408_articolo_soppressione_brown.pdf (consultada el 8 de noviembre de 2019).

Calvino, Italo. 1994. Las ciudades invisibles. Editado por Aurora Bernárdez. Madrid: Siruela.

Chierico, Pier Vittorio y Club Vogatori Pavesi. 2019. II Naviglio di Pavia, 1819-2019. Duecento anni di storia, aneddoti, immagini e curiosità in cento schede illustrate. Pavía: Pime Editrice.

Codara, Giuseppe. 1977. I navigli della vecchia Milano: passato, presente e futuro. Milán: Virgilio. Comune di Milano. "Piano di Governo del Territorio Milano 2030 (PGT)." https://www.comune. milano.it/aree-tematiche/urbanistica-ed-edilizia/pgt-approvato-e-vigente-milano-2030 (consultada el 8 de enero de 2020).

"Turismo. Nel 2019 sfiorati 11 milioni di visitatori." Ufficio Stampa. 2020. https://www.comune.milano.it/-/turismo.-nel-2019-sfiorati-11-milioni-di-visitatori (consultada el 20 de mayo de 2020). Comune di Milano. 1989. Documenti storici dell'acquedotto di milanese. 
Comune di Milano y MM Spa. "Progetto Navigli." https://progettonavigli.comune.milano.it (consultada el 20 de marzo de 2019).

"Progetto Navigli, dossier di progetto." https://progettonavigli.comune.milano.it/incontri-pubblici/dossier-di-progetto/ (consultada el 20 de marzo de 2019).

Dendena, Bianca, ed. 2018. Paesaggi d'acqua. Milano e dintorni. Utopie / 6. Milán: Fondazione Giangiacomo Feltrinelli.

Denti, Giovanni, y Mauri, Annalisa. 2000. Milano: l'ambiente, il territorio, la città. Milán: Alinea Editrice.

Edwards, Paul N. 2003. "Infrastructure and modernity: force, time, and social organization in the history of sociotechnical systems." Modernity and technology 1: 185-226. https://doi. org/0262633108.

Ferrario, Ippolito. y Padovan, Gianluca. 2018. Alla scoperta di milano sotterranea. Milán: Newton Compton Editori.

Finetti, Giuseppe de (Cislaghi, Giovanni, Benedetti, Mara de y Marabelli, Piergiorgio, eds). 2002. Milano: costruzione di una città. Milán: Hoepli Editore.

Fondazione Adolfo Pini. "II Piano Beruto." Storie milanesi. http://www.storiemilanesi.org/approfondimento/il-piano-beruto/ (consultada el 20 de noviembre de 2019).

Guazonni, Edoardo. "La Darsena di Milano.” http://www.edoardoguazzoni.com/la-darsena-di-milano (consultada el 8 de enero de 2020).

Herzog, Jacques y Meuron, Pierre de. 2016. "Expo Milano 2015. Conceptual Masterplan." $A R Q$ 93: 183-141.

Ingold, Alice. 2003. Négocier la ville. Edited by Ecole Française de Rome. París: de l'Ehess.

Koolhaas, Rem y Sainz, Jorge 2014. Rem Koolhaas, acerca de la ciudad. Barcelona: Gustavo Gili.

Lapini, Gian Luca. "Cenni sull'idrografia dell'area milanese." Storia di Milano. 2004. http://www. storiadimilano.it/citta/milanotecnica/fognature/idrografia.htm (consultada el 5 de septiembre de 2019).

Lembi, Pietro. 2006. I/ fiume sommerso: Milano, le acque, gli abitanti. Milán: Editoriale Jaca Book. Malara, Empio. 2012. I/ naviglio di Milano. Milán: Hoepli.

Misculin, Luca. "Il Piano di Milano per favorire I'uso delle bici", /l Post, 29 de abril de 2020. https:// www.ilpost.it/2020/04/29/milano-piste-ciclabili-coronavirus/ (consultada el 23 de mayo de 2020).

Motta, Vittorio. 1989. L'acquedotto di Milano. Milán: Comune di Milano.

Prusicki, Marco. 2016. La Vettabbia, flumen mediolanensis. En Dalle marcite ai bionutrienti. Passato e futuro dell'utilizzo agricolo delle acque usate di Milano, 17-41. Milán: Edizioni Angelo Guerini e Associati

Poggi, Felice y Ufficio Tecnico di Milano. 1911. "Le fognature di Milano: rapporto dell'Ufficio Tecnico all'on. Giunta Municipale su li studi e lavori relativi alla fognatura sittadina nel periodo dal 1868 al 1910." Milán.

Riva, Bonvesin de la. 1974. De magnalibus Mediolani. Milán: Bompiani. 